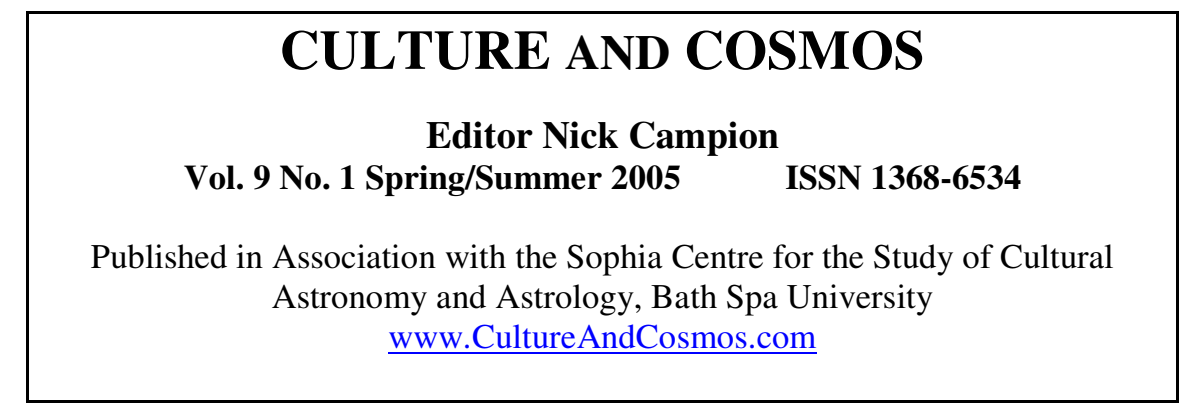

\title{
Editorial
}

\section{David Pingree}

David Pingree, head of the department of the History of Mathematics at Brown University since 1986 and a faculty member since the 1970s, died on the evening of 11 November 2005. David Pingree's contribution to the history of astronomy and astrology, and to the history of ideas, was monumental. The chronological and geographical scope of his work, from Babylonian cuneiform texts, to Hellenistic Greek, Arabic, Iranian and Sanskrit works was immense. Along with his teacher, Otto Neugebauer, he helped establish the history of astrology as a legitimate area of study (rather than as one of George Sarton's 'wretched subjects') and put Brown University on the international map.

An extensive appreciation appeared on the Inside Higher Ed web page:

The department's sole full-time faculty member, Pingree was the kind of professor who liked to take a few motivated students under his wing and foster their own interests within a complex field. His personal library collection is considered to be among the finest in the world for scholars interested in the study of mathematical science in the ancient world.

"Back in the late 1980's, I was looking at graduate programs in history of science, but I had also fallen in love with Sanskrit via a Harvard Extension School continuing-ed course in the language," said Kim Plofker, who received her Ph.D. from the department in 1995. "Sort of on a whim, I asked my Sanskrit professor, 'Is there some way I could combine these interests by studying history of science in Sanskrit?' And she said, 'Well, yes, as a matter of fact, 
there's David Pingree at Brown.' And the more I found out about the department, the more fascinated I was by the range and depth of the interests there."

On Thursday, in an e-mail message sent before the professor died from complications of diabetes, Provost Robert Zimmer acknowledged that administrators were considering eliminating the department altogether, while "appointing any successor to Professor Pingree in another department."

These were terms that did not sit well with the professor, who was planning to retire at the conclusion of this academic year: "In the '70s, we were under a very different administration, and that administration respected what we did," said Pingree in his last interview with The Herald.

Respect for unique university programs is a principle that several faculty members and graduate students are now left to ponder - and fight for - without Pingree's strong voice to help guide the way. "If this department doesn't continue, there will be millions of unread ancient mathematical and scientific texts languishing in libraries, not to mention the loss of an internationally respected center of study," said Alice Slotsky, currently a visiting assistant professor with the department. "This department is one of the few in the world that concentrates on the ancient history of science. ${ }^{1}$

It would be an international scandal and an appalling loss to scholarship if Brown University failed to preserve Professor Pingree's legacy.

\section{Grazia Mirti: an apology}

Due to a series of misunderstandings, material by Grazia Mirti on Galileo's use of astrology was included in Culture and Cosmos Vol. 7 no 1 , the special issue on Galileo's astrology without her prior knowledge. The editors offer their sincere apologies to Grazia and acknowledge her huge contribution to the subject, without which the issue of Culture and Cosmos on Galileo would not have appeared.

\section{For further details see}

http://insidehighered.com/news/2005/11/15/histmath

http://www.ou.edu/islamsci/Current\%20Newsletter-list7.htm

http://www.browndailyherald.com/home/

For Brown University see

http://www.brown.edu/Departments/History_Mathematics/history.html 